\title{
GIL VICENTE Y EL CARNAVAL TRADICIONAL
}

\author{
ANDRÉS JOSÉ POCIÑA LÓPEZ
}

Universidad de Extremadura

\section{Resumen:}

En el siguiente artículo se trata de analizar la repercusión que el Carnaval Tradicional Ibérico tuvo en la obra del dramaturgo portugués Gil Vicente. En la obra de este autor pueden verse distintos reflejos de una tradición acaso milenaria, que afectó a diversos aspectos de los personajes, situaciones y temas de su teatro. Nuestro estudio trata de abordar estas influencias pero sin pretender ser concluyente, sino sólo un punto de partida para estudios sucesivos en el mismo terreno.

PALABRAS CLAVE: Carnaval, Etnografía, Literatura Portuguesa, Teatro Ibérico, Gil Vicente

\begin{abstract}
:
The following work aims to analyze the influences that the Traditional Iberian Carnival had in the Works of the Portuguese dramatist Gil Vicente. In the theatre of this author we can see reflected several themes, from what can be traditions perhaps millenarian; these themes affect to diverse aspects of the personages, situations and subjects of his theater. Our study tries to approach these influences but without trying to be conclusive: it pretends to be only a departure point for successive studies in this area.

KEY-WORDS: Carnival, Ethnographics, Portuguese Literature, Iberian Theater, Gil Vicente.
\end{abstract}


S nuestro propósito, en este artículo, proceder a un análisis sobre el
impacto que han podido provocar, en la obra del dramaturgo renacentista portugués Gil Vicente, las prácticas festivas del Carnaval tradicional europeo, en general, y del Carnaval Ibérico, en particular.

Al emprender cualquier estudio acerca de la relación entre la Literatura y la tradición (o las tradiciones) carnavalescas, es inevitable hacer una referencia, por rápida que sea, a un libro famoso de Mijail M. Bajtín, La Cultura Popular en la Edad Media y el Renacimiento ${ }^{1}$. Una parte de este estudio ${ }^{2}$ llama la atención, a nuestro parecer acertadamente, sobre la importancia de la risa y de lo satírico, ridículo,irónico... en la mentalidad medieval; sin embargo, la tesis subyacente, relativa al papel "revolucionario" de esa comicidad nos parece un poco forzada. Así, por ejemplo, el bufón es considerado como una especie de agente "revolucionario", “desestabilizador": "la concepción cómica destruyó el poder a través de la boca del bufón", llega a declarar el autor ruso ${ }^{3}$. Mayor credibilidad nos merece la idea, también desarrollada por este crítico, de la "risa" y de lo carnavalesco como una válvula de escape de lo subconsciente, de la psique reprimida por el ser humano, idea desarrollada a lo largo de todo este libro.

El libro de Bajtín no es la Biblia, ni como tal debe ser entendido. Quiere esto decir que se pueden (y se deben) ensayar estudios sobre los modelos

\footnotetext{
${ }^{1}$ Hemos usado la siguiente edición, en traducción al español: Mijail Mijailóvich Bajtín, La Cultura Popular en la Edad Media y el Renacimiento. El contexto de François Rabelais, Versión de Julio Forcat y César Conroy, Madrid, Alianza Editorial, 1998 (6 $6^{\mathrm{a}}$ ed.).

2 Bajtín, Op. cit., pp. 59-130. Para la influencia de lo carnavalesco (los disfraces, las groserías...) en Rabelais, p. 178 y ss.; la lectura bajtiniana es de un aprovechamiento "revolucionario", por parte de Rabelais, del discurso carnavalesco: p. 179. Rabelais, figura central del ensayo de Bajtín, sería un "revolucionario" que aprovecharía para su revolución las fiestas populares que mejor expresan la rebeldía social, sobre todo el Carnaval: pp. 177-249.

${ }^{3}$ Bajtín, Op. cit., p. 87.
} 
carnavalescos en la Literatura que se encaminen por rutas distintas a las pautas bajtinianas. Pese al parecer de algunos, que sí tienen a Bajtín como una especie de "profeta" (y nada más alejado del pensamiento bajtiniano, paradójicamente, que pretender ser profeta, o pontificar), lo cierto es que algunos puntos de su obra precisan ser criticados o, por lo menos, revisados. No es éste nuestro proyecto, evidentemente, en las páginas que siguen. Pero sí quisiéramos decir que nuestro estudio tratará de explorar aspectos de lo carnavalesco en la Literatura que no han sido atendidos por el erudito ruso, lo cual, ya de entrada, nos exime de cualquier servidumbre teórica para con Bajtín, así como de cualquier necesidad de crítica directa a su obra. Ésta, sin embargo, será un continuo referente en nuestro trabajo, ya que los valiosísimos hallazgos del estudioso soviético son imprescindibles para una buena perspectiva histórica del fenómeno cultural del Carnaval.

No han faltado lecturas bajtinianas de los autos vicentinos, abordando el tema de la influencia del "discurso carnavalesco" en la Obra de Gil Vicente 4.

\footnotetext{
4. Citaremos los textos de Gil Vicente, siempre que se trate de obras de las que no se conserven pliegos sueltos, por la Copilaçam de todalas obras de Gil Vicente (Lisboa, Joam Âlvarez, 1562), de la que hemos usado la reimpresión fac-símil que figura en el volumen III de As Obras de Gil Vicente, edição sob a Direcção Científica de José Camões, Lisboa, Centro de Estudos de Teatro da Faculdade de Letras da Universidade de Lisboa/ Imprensa Nacional-Casa da Moeda, 2002, y que citaremos en adelante como Copilaçam o, simplemente, Co. Para facilitar la lectura (y la escritura, pues hay detalles gráficos de la época de muy difícil resolución con los medios informáticos actuales) introducimos algunas modificaciones ortográficas, que no sólo no afectan a la realidad fonética del momento, sino que (creemos) trastocan lo menos posible los usos ortográficos entonces vigentes (" $v$ " en lugar de " $u$ " como consonante, modernización de la puntuación, etc...). Las citas estarán localizadas, entre paréntesis rectos, por la numeración del folio según la edición quinientista, precededida de la abreviatura "f." (= "folio") y, seguida, cuando se trate de folios en reverso, de "v." (= [folium $]$ versum) - La Barca do Inferno será citada, al mismo tiempo, por la Copilaçam y por la edición princeps de c.1518, que citamos por la ed. facsímil integrada en el vol. IV de As Obras de Gil Vicente, cit., indicando el número de folio (recto o vuelto); cada cita se ubicará en la edición de la Co., que se marcará como "1562", y, al mismo tiempo, en la ed. princeps, que se marcará como "1518"; las divergencias entre ambas ediciones serán señaladas en nota, pero la localización de cada fragmento será dada en el
} 
Debemos a Maria J. Teles, M. Leonor Cruz y S. Marta Pinheiro un estudio sobre la influencia del "discurso carnavalesco" en la obra vicentina, que se fundamenta en un análisis de la obra vicentina basado directamente en la crítica bajtiniana ${ }^{5}$. José Augusto Cardoso Bernardes discutió bastante acerca del "modelo carnavalesco" en G. Vicente y criticó (acertadamente, a nuestro parecer) la conveniencia de una interpretación en clave "carnavalesca" bajtiniana de la obra de éste: en esas páginas ${ }^{6}$, el profesor Bernardes estudia las formas de aprovechamiento del "discurso carnavalesco" por parte de Gil Vicente, es decir, el impacto que en el dramaturgo portugués pudo tener la visión "carnavalizada" del mundo, o sea, una óptica y una actitud mental propicias a la crítica humorística de la sociedad y del individuo.

No vamos aquí, como hemos adelantado, a enfocar el problema de la influencia del Carnaval desde ese punto de vista. Nuestro estudio no se dirige a un análisis del influjo, en Vicente, de un "discurso", de una "mentalidad" o de una "actitud" (mental o vital) caracterizadas como "carnavalescas". Nos proponemos desviar nuestra atención por derroteros bien distintos. Nuestro estudio tratará de abordar la repercusión, en el maestro del incipiente teatro portugués renacentista, de las formas materiales de las celebraciones carnavalescas propiamente dichas. Ahora bien: semejantes formas materiales, en relación con el Antruejo, son siempre simbólicas: son expresión de sentimientos muy arraigados en las profundidades de la psique humana; de ahí que sea también

cuerpo del texto, entre corchetes, para aligerar las notas. No anotaremos las divergencias que atañan solamente a la ortografía o a particularidades lingüísticas (fonéticas, morfológicas, etc...), prefiriendo, en esos casos, siempre las opciones de 1518.

${ }^{5}$ Se trata del siguiente libro: A Maria J. Teles, M. Leonor Cruz, S. Marta Pinheiro, O Discurso Carnavalesco em Gil Vicente. No âmbito de uma História das Mentalidades. Apresentação de Fernando António Baptista Ferreira, Lisboa, G. E. C. Publicações, 1984.

${ }^{6}$ En Sátira e Lirismo. Modelos de síntese no teatro de Gil Vicente, Coimbra, Por Ordem da Universidade, 1996 , pp. 333-350. 
importante abrir vías de intelección respecto a los significados últimos de prácticas festivas seculares como son las tradiciones del Carnaval, de las que Gil Vicente bebió - opinamos - asiduamente, como nos proponemos demostrar. Así que, en un sentido contrario, las investigaciones sobre el texto vicentino podrían, tal vez, arrojar, incluso, alguna luz sobre ese abismo hondo y oscuro, primigenio, de unas costumbres acaso milenarias.

Es, pues, nuestra intención indagar sobre los ecos que en Gil Vicente pudieron tener las formas del Carnaval Tradicional Ibérico ${ }^{7}$, de las modalidades más arcaicas del Antruejo o Carnestolendas, de cuyas máscaras, cortejos y representaciones creemos que Gil Vicente debió extraer algunas ideas para sus autos. Pero no dejaremos de atender a otras relaciones que la Obra vicentina mantiene con tradiciones literarias medievales europeas más distantes, pero que no han sido consideradas en todo su alcance. $Y$, tal vez, al final de nuestro estudio hagamos algún inciso en implicaciones más profundas relativas a toda esta temática...

Sea como sea, nuestras indagaciones pretenden ser sólo una guía, un comienzo. Es que no da tiempo, en unas pocas páginas, a hacer una pesquisa, todo lo extensa y profunda que se requiere, sobre un tema tan amplio. Por ello, nos limitaremos a abrir caminos, a mostrar algunas vías que, desde nuestro humilde punto de vista, podrían servir como pautas a seguir para trabajos posteriores, más desarrollados; tarea a la que invito a quien quiera realizarla,

\footnotetext{
${ }^{7}$ No han faltado estudios que aborden el tema desde ese enfoque, es decir, que atiendan a la influencia del Carnaval tradicional ibérico en el Teatro. Así, por ejemplo, hay estudios muy interesantes sobre la influencia del Antroido de Galicia, al que aquí haremos referencia de un modo muy especial, en el Teatro gallego, como el de José María Paz Gago, "Teatro da Subversión. As tradicións do Antroido no teatro galego contemporáneo", en Cinguidos por unha arela común. Homenaxe ó profesor Xesús Alonso Montero, coord. de Rosario Álvarez e Dolores Vilavedra, Santiago de Compostela, Universidade, 1999, tomo II, pp. 1125-1138. Sí faltan, sin embargo (a nuestro modo de ver) estudios de esta índole a propósito del teatro de Gil Vicente.
} 
aunque no descarto, en modo alguno, afrontarla de un modo más ambicioso en futuros trabajos.

\section{Carnaval Tradicional y Tradiciones carnavalescas arcaicas en la Península}

\section{Ibérica}

Cuando se analiza la presencia, en la obra vicentina, de recuerdos de las tradiciones más antiguas relacionadas con las antiguas fiestas de Carnestolendas, se suelen establecer, por lo común, paralelos con los géneros medievales franceses y de la Europa Germánica más marcados por las celebraciones carnavalescas: las farces, las sotties, las festa stultorum ${ }^{8}$... No es raro, pues estas representaciones dramáticas, francesas, alemanas o flamencas son muy bien conocidas, mientras que la presencia de dramas semejantes en la Península Ibérica a lo largo de la Edad Media es punto aun no esclarecido. Sin embargo, lo cierto es que las festividades básicas de las que bebían esas representaciones, las festividades de Antruejo o Carnaval, son comunes a toda Europa desde los mismos albores de la Edad Media. Por ello, es pensable que las tradiciones de las que proceden el sot, los Episcopi Stultorum y otros personajes de la farsa medieval centroeuropea y francesa estuviesen también extendidas por suelo ibérico. Esta sospecha, en realidad, es casi certeza, debido a la existencia, aquí y allá, en nuestra Península, de mascaradas y prácticas carnavalescas muy antiguas y que guardan paralelos más que evidentes con las carnavaladas medievales que dieron origen a la farsa medieval. La Etnografía,

\footnotetext{
8 El estudio más completo, desde nuestro punto de vista, acerca de la influencia, en Gil Vicente, de la sottie, la farsa francesa y otros géneros farsescos medievales, es el de Cardoso Bernardes: Sátira e Lirismo..., cit., pp. 200-285.
} 
por lo tanto, viene a confirmarnos aquello que la Historia Literaria, debido a la falta de textos, es incapaz de certificar o negar: la existencia de festividades populares, de Carnaval o de invierno (en un sentido más lato), en la Península Ibérica, muy semejantes a las del resto de Europa. Y seguro que Gil Vicente, aparte del conocimiento más o menos directo que pudiese tener de las representaciones francesas, flamencas o alemanas, debió prestar atención, más de una vez - dada su sensibilidad hacia toda manifestación de la cultura popular - a estas festividades de Carnaval, de la que seguro que extrajo más de una idea, al concebir personajes típicos, situaciones dramáticas o cuadros escenográficos.

Ha sido, desde luego, Julio Caro Baroja9 ${ }^{9}$ quien mejor ha sabido delinear, en toda su extensión y profundidad, los contornos inmensos de la variedad y complejidad de las prácticas carnavalescas, de su simbolismo, su colorido y realizaciones materiales, plásticas, dramáticas (o paradramáticas). El eminente etnógrafo e historiador vasco nos muestra en su libro un panorama que abarca todas las distintas modalidades del festival que, sobre todo a partir del siglo XVIII, conocemos en todas las lenguas de nuestra Península por el nombre italianizante de Carnaval, pero que conserva aún en las lenguas románicas hispánicas otros nombres más antiguos, como Carnestolendas y Carnal en castellano, Carnestoltes en catalán, y Carnestultas en el dialecto aragonés, Entrudo en portugués "padrão" y, a veces, en las Canarias, Entruido en portugués dialectal y gallego, Antroido, Entroido, Introido, Antruido, Entrudio y similares en gallego, Entruido o Entroido en el Bierzo, Antroido, Antroiro o Antroxo en Asturias, y Antruejo (con la variante ortográfica, en el castellano antiguo o, a veces, fonética, en el español dialectal, "Antruexo") en castellano

\footnotetext{
${ }^{9}$ En El Carnaval (Análisis Histórico-Cultural), Madrid, Taurus, 1979.
} 
antiguo y dialectal ${ }^{10}$. Es especialmente importante señalar, también siguiendo a Caro Baroja, que las prácticas carnavalescas no se ciñen, en muchas ocasiones, a las consabidas fechas de domingo, lunes y martes precedentes al Miércoles de Ceniza, sino que las mascaradas y otros rituales propios de esas fechas se extienden a lo largo de todo un período que, a veces, abarca buena parte del Invierno, incluyendo (desde el punto de vista folklórico) fechas como San Esteban, el Día de los Santos Inocentes, Reyes, San Antón (es decir, San Antonio Abad), Candelaria, San Blas, y los curiosísimos Jueves de Compadres y Comadres, Jueves “Gordo" o “Lardero" (en Castilla), el Miércoles de Ceniza y el domingo de esa misma semana (Domingo "de Piñata")11.

Se trata de unas fiestas de remotos orígenes paganos, insertadas en el Año Litúrgico Cristiano como una especie de sobrevivencia, a menudo conflictiva y prohibida por las autoridades eclesiásticas ${ }^{12}$. Sus raíces se hunden en algunas celebraciones del Paganismo Clásico, como las Saturnalia romanas (del 17 al 21 de Diciembre) ${ }^{13}$ y otras festividades semejantes ${ }^{14}$.

Las tradiciones típicas de las mascaradas carnavalescas han dejado profundas huellas en la obra de Gil Vicente. Para empezar, los personajes que protagonizan las mascaradas ibéricas tradicionales, tanto por su indumentaria como por sus modos de actuación, peculiar idiosincrasia y por su carácter irresponsable, inocente, tienen una relación más que evidente con los bobos (parvos) presentes en diversos autos de Gil Vicente.

\footnotetext{
10 Caro Baroja, op. cit., pp. 33-42.

11 Caro Baroja, Op. cit., pp. 43-46.

12 Caro Baroja, Op. cit., pp. 150-153 y 293-297.

13 Caro Baroja, Op. cit., pp. 298-304.

14 Como las Lupercalia, que deben haber influido en la costumbre, de muchos enmascarados del Carnaval tradicional, de fustigar al público con vejigas o pequeños látigos (Caro Baroja, op. cit., pp. 345-347); o, también, las Matronalia, de posible repercusión en las tradiciones de los "Jueves de Comadres" de buena parte de la Península Hispánica (ibidem, pp. 368-389).
} 


\section{[E1 "parvo" vicentino y las mascaradas tradicionales $\left.{ }^{15}\right]$}

A fuer de gran conocedor de las costumbres y rituales folklóricos, Gil Vicente debía tener continuamente presentes las mascaradas más arcaicas del carnaval ibérico, que en su época debemos presumir, desde luego, mucho más extendidas que en la actualidad, así que no es descabellado suponer que personajes parecidos a los cigarróns gallegos o a los zangarrones zamoranos debían protagonizar, en su tiempo, los entrudos portugueses incluso en Lisboa, sede de la Corte, donde se representaron buena parte de los autos de nuestro autor. Gil Vicente debió recibir influencias de esas mascaradas y las reflejó en su teatro, sobre todo como caracterización de sus bobos o parvos. Pero en esa caracterización debieron influir también otros modelos, franceses o de otras partes de allende los Pirineos.

La influencia en Gil Vicente del carnaval tradicional europeo - tal vez a través de la modalidad ibérica del "antruejo" arcaizante (que pervive en el "entroido" gallego y en el "entrudo" portugués de algunas partes del Norte), aunque también a través de un género teatral de la Edad Media, la Sottie llegará a concretarse, $\mathrm{o}$, incluso, a encarnarse, en un personaje típico: el parvo. El parvo vicentino es uno de los precedentes más claros de los bobos del teatro renacentista y barroco español, también difundido por otros países europeos. Pero, como acabamos de adelantar, tiene a su vez otros precedentes, esta vez del teatro medieval europeo, sobre todo francés: el sot ${ }^{16}$, tipo fundamental de un

\footnotetext{
15 Incluyo en este apartado algunos materiales, muy ampliados, ya empleados por mí en mi reciente libro Gil Vicente y las Naves de los Locos, Salamanca, Luso-Española de Ediciones, en sus pp. 141-146, aunque, en esta ocasión, usados con una finalidad muy distinta.

16 Nótese que la palabra "sot", en francés, equivale a "bobo", igual que la palabra portuguesa "parvo".
} 
género especial de farsas, las sotties, emparentadas con otras clases de farsas protagonizadas por asnos, como las "fiestas de los burros" y los "juicios de los burros"17. De hecho, el sot tiene mucho que ver con los burros, hasta el punto de que el ilustrador del libro de Sebastian Brant, Das Narrenschiff, caracterizará a sus archiconocidos necios (Narren) con orejas de burro; aparte de esto, hay que recordar la consuetudinaria ${ }^{18}$ homologación del idiota con el burro.

Como puso de manifiesto Bajtín ${ }^{19}$, la relación del loco y la locura con los festejos carnavalescos comienza históricamente con unas celebraciones medievales, las "fiestas de los locos" (Festa Stultorum, Fatuorum o Follorum) ${ }^{20}$, en que participaban sobre todo colegiales y clérigos en los días de San Esteban, día de los Inocentes, de la Trinidad y el día de San Juan Evangelista, fechas que, aunque no directamente integradas en el ciclo del Carnaval, corresponden a festejos que, aún en nuestros días, se celebran a nivel popular con "mascaradas" en muchas partes, mascaradas que se inscriben en un ciclo amplio de "mascaradas de Invierno" 21, de las que el Carnaval es sólo una variedad (eso sí, la más importante de todas ellas). En principio, estas "fiestas de los locos" eran perfectamente admitidas por las autoridades eclesiásticas, pero acabaron por ser prohibidas, merced al "desenfreno" que en ellas llegaba a hacerse patente; a causa de esa prohibición, las fiestas fueron relegándose (sobre todo en Francia)

\footnotetext{
${ }^{17}$ Sobre las relaciones entre los parvos vicentinos, la sottie y las "fiestas de los burros", "juicios de los burros" y otras celebraciones relativas a los asnos, cfr. José Augusto Cardoso Bernardes, op. cit., pp. 241 (y nota), 250 (y nota).

18 Y más que rutinaria, pues el asno es, en realidad, un animal de gran inteligencia.

${ }^{19}$ Op. cit., pp. 72-73.

20 Sobre las "fiestas de los locos", el carnaval y los bobos, además de Bajtín, cfr. Cardoso Bernardes, op. cit., pp. 236 (y nota) y 237. Cfr., asimismo, Maria J. Teles, M. Leonor Cruz, S. Marta Pinheiro, op. cit., p. 15. Sobre la relación entre el Carnaval y el teatro burlesco (en especial el vicentino) y el origen carnavalesco de personajes como los parvos, ibidem, p. 16.

${ }^{21}$ Cfr. Rodríguez Pascual, "Mascaradas de invierno en la raya", en Estudios Portugueses. Revista de Filología Portuguesa, $\mathrm{n}^{\mathrm{o}}$ 4(2005), pp. 201-208.
} 
paulatinamente al ámbito tabernario y callejero, e incluso acabaron por trasladarse de fecha, a la época del Carnaval propiamente dicho, esto es, al Mardi Gras'22. Caracterizaban a estas fiestas la inversión carnavalesca, las parodias, los disfraces, mascaradas y danzas obscenas; era una fiesta muy antigua, pero se mantuvo, por lo menos en Francia, hasta bien entrado el siglo $\mathrm{XV}$, adquiriendo corrientemente la forma de "degradaciones de los diferentes ritos y símbolos religiosos transferidos al plano material y corporal", en palabras de Bajtín²3. Su principal cometido era servir como de "válvula de escape" a una "segunda naturaleza" escondida en el ser humano, naturaleza ridícula, obscena, primitiva, que durante el resto del año se hallaba reprimida por el ascetismo de la vida eclesiástica ${ }^{24}$. "Fiestas de los Locos" y "Parrandas de los Tontos" (como la de Los Verdiales, prov. de Málaga) se han representado, hasta hace relativamente poco, en buena parte de Andalucía, en Navidad y, en general, a lo largo de todo el invierno ${ }^{25}$ : acaso una pervivencia de ello pueda rastrearse en las "chirigotas" y comparsas del carnaval gaditano.

Los autos de Gil Vicente en que hace acto de presencia el parvo son los siguientes: Barca do Inferno, Nau de Amores, Frágua de Amor, Auto da Festa, Auto da Fama, Velho da Horta y Floresta de Enganos, según Maria José Palla26; José Augusto Cardoso Bernardes añade, a ésos, otros autos en que esta figura tiene

\footnotetext{
22 Bajtín, op. cit., p. 72.

23 Bajtín, Loc. cit.

24 Bajtín, Loc. cit..

${ }^{25}$ Caro Baroja, op. cit., pp. 331-335.

26 Maria José Palla, "O parvo e o mundo às avessas em Gil Vicente - algumas reflexões", en Temas Vicentinos - Actas do Colóquio em torno da obra de Gil Vicente (Teatro do Bairro Alto, 1988), Lisboa, Icalp, 1992, pp. 87-100, en nota de la p. 87.
} 
también una importancia mayor o menor: Comédia de Rubena, Tragicomédia Pastoril da Serra da Estrela y el Auto Pastoril Português' ${ }^{27}$.

Podemos suponer, siguiendo a la profesora Maria José Palla, que en todos estos autos vicentinos en los que figura el parvo, éste debía aparecer caracterizado como los viejos sots de las sotties medievales francesas y del Norte de Europa, antes mencionadas: vestido con túnica a dos colores (normalmente verde y amarilla), con cencerros o campanillas en los brazos, la cabeza o las piernas y tocado con algún gorro extravagante, tal vez con orejas de burro, como acontece también en el caso de los locos que aparecen en los grabados de Das Narrenschiff28. De tal figura existen representaciones plásticas en el arte portugués manuelino, como el "louco" esculpido en la capilla del crucero del Convento de Cristo, en Tomar, que, según Paulo Pereira29, aparece sonriente, revestido de follaje y lleva alas en la cabeza y cascabeles (relacionables, claramente, con los cencerros). Una caracterización que, además, se corresponde aproximadamente con la que era usual entre los bufones medievales y renacentistas, y habrá de hacerse también habitual entre los necios de la escena europea del Renacimiento tardío y Barroco, sean los "Falstaffs" de Shakespeare o los bobos del teatro barroco español. Se trata de un personaje cuyo origen está, en realidad, en las fiestas del Carnaval, como también resaltan la profesora Palla $^{30}$ y otros investigadores; esta última circunstancia nos interesa, evidentemente, de manera muy especial aquí.

27 Cardoso Bernardes, op. cit., cit., p. 260.

28 Cfr. Maria José Palla, op. cit., especialmente pp. 88-89, donde se mencionan otras características comunes al sot y al parvo, aparte de las citadas, como sus habilidades acrobáticas, su entrada en escena con gran ruido y algarabía, y otras.

29 Paulo Pereira, "Gil Vicente e a contaminação das artes. O Teatro na Arquitectura - o caso do Manuelino", en Temas Vicentinos, op. cit., pp. 101-123, en p. 113.

30 Art. cit., p. 88. 
Pero lo que más nos importa resaltar ahora es cómo algunos de los detalles básicos que, normalmente, caracterizaban al sot, y caracterizarán al parvo vicentino o a los bobos posteriores, como pueda ser el empleo de cencerros ("chocalhos") para crear una "música" rústica y animal, primitiva, "tangendo a chocalhada" 31 , así como los trajes extravagantes de colores vivos, o el carácter animal del "bobo", son también rasgos que distinguen a los personajes ("máscaras") tradicionales más arcaizantes del carnaval ibérico, en especial del carnaval tradicional gallego y de algunas partes de Portugal, o de parajes zamoranos, salmantinos y extremeños fronterizos con este país.

En realidad, se trata de mascaradas tradicionales que salpican, aquí y allá, buena parte de la geografía ibérica, en particular, y Europea, en general. Son famosas las mascaradas de la provincia vasco-francesa de Soule, o Zuberoa, con su "txerrero", "artza” y "gathia"32, así como el "zaldiko"33 de buena parte del País Vasco ${ }^{34}$, personaje que se disfrazaba de caballo; las mascaradas de "guirrios", "bardancos", "sidros" o "zamarrones" asturianos ${ }^{35}$, que se visten de pieles, llevan cencerros y asustan a la gente con látigos ${ }^{36}$. En las montañas de León se conocen (o conocían) los “zafarrones” y sus “zafarronadas”37, así como los “zarromacos", "zarramacos" o “zorromocos" de Santander, así como los "mozorrak o "zomorruak" vascos 38 . En la Cataluña pirenaica y Alto Aragón existían tradiciones semejantes, hoy prácticamente desaparecidas ${ }^{39}$.

\footnotetext{
${ }^{31}$ M. J. Palla, op.cit., p. 88.

32 Caro Baroja, op. cit., pp. 180-182.

33 Caro Baroja, Op. cit., pp. 206 y 209-210.

34 Sobre éste y otros aspectos del Carnaval tradicional vasco, Caro Baroja, op. cit, pp. 196-214.

35 Caro Baroja, Op. cit., pp. 216 y ss.

36 A menudo, vejigas, por lo que también se les conoce como "bexigueros".

37 Caro Baroja, op. cit., p. 230.

38 Caro Baroja, Op. cit., pp. 232-233.

${ }^{39}$ Caro Baroja, Op. cit., pp. 245-251.
} 
En la provincia de León, sobre todo en la Maragatería, tenían fama los "guirrios" o "birrios"40, así como los conductores del arado en una arcaica celebración, llamada, precisamente, la Fiesta del Arado: en ella, ciertos hombres, disfrazados unos de varones y otros de mujeres, tiraban de un arado, montados sobre zancos, vestidos de pieles y adornados con cencerros, llamados "zamarrones" los que se disfrazaban de hombres, y "xiejas" [sic] las que lo hacían de mujeres; todos ellos eran conducidos por una especie de capitán, el "birria" o "guirria"41. En Rabanal del Camino, la Noche de Año Viejo salían los "zamarracos"42, vestidos con pieles de oveja, portando grandes cencerros o "campanos" (de ahí que se les conociese como “zamarracos campaneiros") y tapándose la cara con máscaras de viejos desdentados; además, el 14 de septiembre, los "birrias" bailaban, en esa misma localidad, danzas de "palos y cintas"43, muy parecidas a la popularísima Dança dos Pauliteiros de Miranda do Douro (distrito de Bragança, Portugal). Es una pena que estas festividades ancestrales estén en franco retroceso, cuando no totalmente extintas.

En Extremadura, la comarca donde mejor ha sobrevivido el antruejo al tipo tradicional es la de las Hurdes, donde el Domingo de Carnaval (llamado, como en portugués, Domingu Gordu en el dialecto - castúo - local) aparecen, sobre todo en la población de Martilandrán, las "carantoñas": hombres del pueblo, disfrazados con pieles de cabras o zorras, cara tiznada y multitud de cencerros atados a la cintura ${ }^{44}$. En Fragosa, cerca de Martilandrán, las carantoñas salen el propio Martes de Carnaval, mientras que en El Gasco se

\footnotetext{
40 Caro Baroja, Op. cit., p. 234.

${ }^{41}$ Caro Baroja, Op. cit., pp. 239-240.

42 Caro Baroja, Op. cit., p. 241.

43 Caro Baroja, Op. cit., p. 242.

44 Javier Marcos Arévalo, Fiestas Populares Extremeñas, Badajoz, Editora Regional de Extremadura, 1984, p. 9.
} 
corre, ese mismo día, el "burru-antrueju", en realidad dos hombres cubiertos por una manta: el "burru-antrueju” recorre las calles del pueblo atacando a los transeúntes; a veces, se trata de burros de verdad, que corren por las calles con la albarda puesta del revés (apelo claro a la inversión carnavalesca) ${ }^{45}$. En La Huetre, pedanía de Los Casares, había un ritual del arado parecido al de la Maragatería, así como una suelta de la "vaca-antrueja", semejante al "burru" de El Gasco ${ }^{46}$. Fuera de las Hurdes, hay que recordar la tradición de las "carantoñas" o "carantamaulas" de Acehúche, esta vez exhibidas en la festividad de San Sebastián ${ }^{47}$.

Estas mascaradas se relacionan, de modo muy palpable, con otras muy distantes, de Grecia (sobre todo los "kalogheroi”, "katsiveloi" y "koritsiai" de Tracia $^{48}$ ) y del Norte de África, en especial de Marruecos ${ }^{49}$. Julio Caro Baroja ha apuntado hacia la posibilidad de que estas mascaradas procedan directamente de los ritos dionisíacos ${ }^{50}$; por tanto, en último análisis, estarían relacionados con los orígenes mismos del Teatro.

Pero, en terreno peninsular ibérico, las "máscaras" (o disfraces) más representativos y mejor logrados son, desde luego, los del antruejo ("entroido") rural galaico más primigenio, cuyo colorido y vistosidad los aleja un tanto del aspecto tosco y rudo de los disfraces de "guirrios", "zamarrones", etc..., aproximándolos, por el contrario, de los vestidos de bufones y bobos de corte, que eran, desde luego, los que debían llevar los parvos vicentinos. Los disfraces gallegos suelen consistir, en efecto, en trajes de colores muy vivos; vestidos muy

\footnotetext{
${ }^{45}$ Marcos Arévalo, Loc. cit..

46 Marcos, Op. cit., p. 10.

${ }^{47}$ Marcos, Op. cit., p. 32.

${ }^{48}$ Caro Baroja, Op. cit., pp 269 y ss.

${ }^{49}$ Caro Baroja, Op. cit., pp. 280-282.

${ }^{50}$ Caro Baroja, Op. cit., pp. 274-280.
} 
llamativos, pero, a la vez, ridículos y extravagantes; las "máscaras"51 gallegas llevan cencerros y cascabeles para hacer ruido y pegan a la gente con "mallos", palos, "látegos" o "bexigas" de vaca o cerdo; se tocan con gorros parecidos al "gorro frigio" o a las "mitras" de los obispos y, para remarcar su carácter animal, primordial, telúrico, cuelgan del reverso de sus gorros pieles de bestias (cabras, zorros... $)^{52}$. Los hombres que se disfrazan llevan faldas, grandes polainas y zapatos con borlas, lo que les da un cierto aspecto femenino,

51 De este modo se denomina no sólo a los disfraces carnavalescos, sino también a los individuos que los visten.

52 Cfr. Xosé Manuel González Reboredo, "Festas Cíclicas", en Antropoloxía: Relixión. Crenzas. Festas, vol. XXVII de Galicia, dir. de Francisco Rodríguez Iglesias, A Coruña, Hércules de Ediciones, 1999, pp. 260-353, en pp. 296-301. Igualmente, Vicente Risco, “Etnografía. Cultura Espritual [sic]", en Ramón Otero Pedrayo (org.), Historia de Galiza, vol. I, pp. 255-762, en pp. 621628. De esa forma están caracterizadas (cambiando algunos detalles en una u otra) las "máscaras" más típicas del "entroido": los "felos" de varias partes de las provincias de Lugo y Ourense (Vicente Risco, op. cit., p. 621), los "volantes" de Chantada (prov. Lugo, González Reboredo, op. cit., pp. 296-297), los "vellos", "borrallosos", "borralleiros" o "cinseiros" de varias partes de Galicia (Vicente Risco, op. cit., p. 621), las "charrúas" de Allariz (prov. Ourense), los "paiasos" de Rabeda y los "irrios" de Teixeira (Ourense), los "peliqueiros" de Pedrafita de Chantada y de Carracedo (Lugo), los "farandulleiros" de Entrimo (Ourense) [ibidem], los "felos" de Maceda (Ourense, González Reboredo, op. cit., p. 299), las "pantallas" de Xinzo de Limia (Ourense, ibidem, p. 298), los "troiteiros" de Bande (Ourense), los "foliós" de Manzaneda (Ourense), los "boteiros" de Viana do Bolo y Vilariño de Conso (Ourense) [ibidem, p. 299], los ya desaparecidos "choqueiros" de Abegondo y Bergondo (Coruna, ibidem, p. 301) y, sobre todo, los "cigarróns", "peliqueiros" o "piliqueiros" del valle de Monterrei, con Verín, y del valle de Laza (Ourense: ibidem, pp. 298-299; Risco, op. cit., p. 622), también denominados "felos", "murrieiros" y "charrúas" (Vicente Risco, op. cit., p. 622); personajes que tienen una relación más bien indirecta con los "lanceiros", "madamitos", "vellos" y "zapateiros" del Antroido de Cotobade (prov. de Pontevedra, cfr. Caro Baroja, op. cit., pp. 223-225). Todos estos personajes carnavalescos se relacionan con otros, de diversas partes de la Península y otras zonas de Europa: los "zamarrones" de Asturias, los "zapantzar" de Ituren y Zubieta (Navarra) y personajes similares de Trás-os-Montes, Zamora y otras partes de la Península Ibérica (de los que después hablaremos), otros enmascarados similares de Arlès-sur-Tech (Francia), o los "Perchten" alemanes y los "kalogheroi" griegos (González Reboredo, op. cit., pp. 301-302) Sobre el Entroido gallego, en general, cfr., igualmente, Xosé Ramón Mariño Ferro, Antropoloxía de Galicia, Vigo, Xerais, 2000, pp. 466-477 (sobre las "máscaras", en particular, ibidem, pp. 469-471); también, Julio Caro Baroja, op. cit., pp. 223-226; sobre el Entroido y su inserción en el ciclo anual festivo gallego, cfr. Xosé Manuel González Reboredo, A Festa de San Xoán, Vigo, Ir Indo Edicións, 1989, pp. 14-16. 
travestido; a veces, los enmascarados gallegos se limitan a ponerse la ropa al revés, con lo de fuera hacia dentro, o se visten con ropa vieja y mal puesta ${ }^{53}$ : todo ello es muestra de la típica inversión característica del Carnaval, la cual caracteriza a no pocos parvos vicentinos ${ }^{54}$.

Aparte de Galicia, otras dos provincias (respectivamente, portuguesa y española) donde se han conservado con gran fidelidad las costumbres ancestrales relativas al Carnaval son, sin duda, Trás-os-Montes y Zamora, provincias que conforman, hasta cierto punto y en muchos aspectos, una especie de región etnográfica individualizada, sobre todo en las localidades próximas a la frontera que comparten.

En Trás-os-Montes hay una gran riqueza de mascaradas tradicionales ${ }^{55}$. Son especialmente conocidos los "caretos" de Podence, aldea del concelho de Macedo de Cavaleiros ${ }^{56}$. En las tierras de Barroso - una comarca, colindante con Galicia, que se cuenta entre las más arcaizantes de la provincia transmontana los mozos, mozas, hombres, mujeres y niños salen a la calle, el "Domingo Gordo" y la "Terça-Feira de Entrudo", todos disfrazados, con ropas viejas y la

\footnotetext{
${ }^{53}$ Es el caso de los "curruvelos" de Moaña (Pontevedra) o las "abutardas" de Sande (Cartelle, Ourense) [González Reboredo, op. cit., p. 296].

54 La relación, en Gil Vicente, entre los parvos y el "mundo al revés" ("mundo às avessas") ha sido puesta de relieve por Cardoso Bernardes, Sátira e Lirismo..., cit., pp. 238 y 241-242, y M. J. Palla, art. cit., pp. 90-91. Sobre el carnaval y el "mundo às avessas", cfr., igualmente, Maria J. Teles, M. L. Cruz, S. M. Pinheiro, op. cit., p. 18.

55 Son especialmente relevantes las fiestas de los "caretos" de Podence (concelho de Macedo de Cavaleiros, véase la nota siguiente), de Pinela (concelho de Bragança) y de Rebordelo (concelho de Vinhais), así como las Festas do Chocalheiro, en la aldea de Bemposta (concelho de Mogadouro). Sobre todas estas mascaradas trasmontantas puede obtenerse información actualizada en la siguiente página web: http://www.bragancanet.pt/arte/mascaras.html. Este "chocalheiro" de Bemposta puede ser puesto en relación, evidentemente, con los "chocalhos" o cencerros, así como con los "choqueiros" del carnaval gallego (nombre, en este caso, derivado de "chocas" = "chocalhos").

56 Sobre los "caretos" de Podence puede encontrarse información actualizada en Internet: véase, por ejemplo, la página web: http://www.caretosdepodence.no.sapo.pt, o esta otra: http://www.bragancanet.pt/arte/podence.html.
} 
cara tapada, siendo muy típica la "norma" (relacionada una vez más con la inversión) de que los hombres se vistan de mujeres, y viceversa ${ }^{57}$. Son comunes allí las "máscaras", o enmascarados, al tipo gallego, llamados en Tourém "fulipeiros" y, en otras partes de la Terra do Barroso, "farrapeiros", "caretos" o "farrapões" 58 . Estos "caretos" se visten "com croças de palha, chapéus velhos, rotos, peles caseiras de cabra, odres de farinha, mantas velhas, etc." 59 . En toda la zona zamorano-trasmontana, sobre todo en las tierras de frontera, se repiten mascaradas similares, según ha puesto de relieve el profesor Francisco Rodríguez Pascual60. Tales mascaradas no se circunscriben únicamente al tiempo de carnaval, como ya hemos adelantado, sino que se reparten entre varias ocasiones festivas del invierno: Navidades, San Esteban, Reyes ${ }^{61} \ldots$ Los disfraces con pieles de animales y grandes cencerros 62 , así como las persecuciones por las calles, luchas entre personas o entre animales, robos rituales y "mouriscadas"63 centran, en todos ellos, la atención de los participantes en la fiesta.

\footnotetext{
57 António Lourenço Fontes, Etnografia Transmontana, I - Crenças e Tradições do Barroso, Montalegre, Concelho de Montalegre, 1974, p. 111.

58 Lourenço Fontes, Loc. cit.

${ }^{59}$ Lourenço Fontes, Op. cit., p. 112.

${ }^{60}$ En "Mascaradas de invierno en la raya", art. cit.

61 Op. cit., passim.

62 Las máscaras más famosas son los "zangarrones" de Sanzoles y Montamarta, los "tafarrones" de Pozuelo de Tábara, los "carochos" de Riofrío de Aliste, los "cencerrones" de Abejera y Sesnández (todo ello en la provincia de Zamora), los "caretos" de Valverde (Trás-os-Montes) y de Riodonor/ Río de Honor (población rayana, con parte en Portugal y parte en España), los "caretos" y "filandorras" de Constantim (Trás-os-Montes), los "carachos" de Carbajales (Zamora), los "farândolos" de Bemposta (Trás-os-Montes), los "zamarrones" y "birrias" de Tábara o los "guirrios" (¿relacionados con los "irrios" gallegos?) de Benavente, también en Zamora: cfr. Rodríguez Pascual, op. cit., p. 202 y ss.

${ }^{63}$ Rodríguez Pascual, Op. cit., p. 203 y p. 205.
} 
En todo el resto de Portugal ha habido también, un poco por todo el territorio nacional, tradiciones carnavalescas semejantes ${ }^{64}$. Hoy en día, estas tradiciones han desaparecido en muchos lugares, pero existían en Almeida, en Almofala (concelho de Castro Daire) ${ }^{65}$, o en Mondim da Beira ${ }^{66}$, donde, en general, los enmascarados andaban cubiertos de cencerros y vestidos de pieles, sobre todo de oveja, y armados de palos en las manos, o de mocas, con que ahuyentaban a la gente, tras la cual corrían; a veces se armaban de cardas, por lo que recibían el nombre de "cardadores" ; a veces, los enmascarados eran hombres vestidos de mujeres (de nuevo, el fenómeno de la inversión carnavalesca). En Lisboa era muy conocido el "cheché", desaparecido hace décadas: iba vestido a la moda del siglo XVIII y portaba "um grande facalhão de madeira", con el que se dirigía a los viandantes, "pedindo dinheiro com falsas ameaças"67. Otro tipo de carnavales, con "gigantes y cabezudos", música de gaitas (gaita-de-foles) y otros rasgos arcaicos semejantes, como los de Torres Vedras, escapan a los presupuestos de este estudio, por lo que no entraremos a analizarlos.

Lamentablemente, los carnavales “à brasileira" han acabado, en buen número de ocasiones, con todas estas costumbres antiguas. Hace pocos años pudimos asistir a una de esas "brasileiradas" (lo decimos desde nuestro mayor respeto por el Brasil y su cultura), incluso con un pequeño "sambódromo" improvisado al efecto, en Figueira da Foz. El carnaval brasileiro es un

\footnotetext{
64 Para una visión de conjunto sobre los carnavales rurales en Portugal, cfr. Rodney Gallop, Portugal. A Book of Folk Ways, Cambridge, At the University Press, 1961, pp. 107-121.

${ }^{65}$ Leite de Vasconcelos, Etnografia Portuguesa - Vol. VIII, organizada por M. Viegas Guerreiro com a colaboração de Alda da Silva Soromenho e Paulo Caratão Soromenho; Prefação de Orlando Ribeiro, Lisboa, Imprensa Nacional/ Casa da Moeda, 1982, pp. 148-149.

${ }^{66}$ Leite de Vasconcelos, Op. cit., p. 149.

${ }^{67}$ Leite de Vasconcelos, Op. cit., p. 151.
} 
espectáculo grandioso... ¡en su lugar de origen! Estos espectáculos no son más que torpes parodias de esa grandiosidad. Aunque bien es cierto que la parodia ha sido siempre consustancial al carnaval, desde los sots y los parvos vicentinos hasta las chirigotas de Cádiz.

En general, los enmascarados del "entroido" gallego, del "antruejo" o "antruido" zamorano y del "entrudo" portugués van haciendo ruido con sus cencerros o campanillas, no hablan nunca, actúan como anónimos y llevan colgando pieles de bestias ${ }^{68}$ : todo ello los relaciona con el Reino Animal. No es (o, por lo menos, no era) raro, de hecho, que, en los carnavales gallegos, se sacasen a desfilar, como parte del cortejo, burros, vacas o bueyes, o que la gente se disfrazase de toros, de vacas o incluso de osos, en ocasiones vistiendo las pieles de esos animales ${ }^{69}$; estas peculiaridades se repiten en los carnavales zoomorfos de partes de Trás-os-Montes y las provincia de Zamora y Salamanca $^{70}$. Los más célebres enmascarados gallegos, los "peliqueiros" o “cigarróns" de Laza y Verín, no pueden hablar durante su paseo por las calles de la aldea, golpean a la gente al pasar, están ávidos de vino y de comida, no saben contenerse, atacan a las mujeres, revelan tendencias libidinosas, están poseídos y dominados por el aspecto carnal, primigenio, instintivo, del ser humano, según pone de manifiesto González Reboredo ${ }^{71}$. Haciendo una revisión del comportamiento de los “cigarróns", Vicente Risco declaraba que

\footnotetext{
68 González Reboredo, “Festas Cíclicas”, cit., p. 302.

69 Loc. cit., pp. 302-305. Sobre los disfraces de animales (vacas, toros, osos, burros) y de diablos en el carnaval gallego, cfr., así mismo, V. Risco, “Etnografía...", pp. 626-627.

70 Sobre todo es importante la "obisparra" que se desarrolla en varias poblaciones de la comarca de Sanabria, así como las "vacas bayonas" de diversos puntos de Zamora y Salamanca, los desfiles de mulas en puntos de Sayago y la Tierra del Vino, el "caballico" de Villarino de Trasla-Sierra o la Vaquilla de Palacios del Pan (sitios, éstos últimos, pertenecientes a la provincia de Zamora): cfr. Rodríguez Pascual, art. cit., p. 202, 203-204 y 207-208.

${ }^{71}$ González Reboredo, “Festas Cíclicas”, cit., p. 302.
} 
éstos no hablan, andan a saltos, andan pidiendo que se les invite a comer o beber, golpean a la gente con total impunidad; "ninguén pode pronunciar o seu nome" y "aquil en quen bate nono pode tomar a mal"; en contrapartida, "o cigarrón non se pode enfadar nin levar a mal os aldraxes"72. Semejante es, también, el comportamiento de los "caretos" de la Terra do Barroso: "fazem-se aleijados, coxos, cegos, burros, mudos. Levam paus para se defenderem [...], batem nas pessoas" y "embora ninguém deva levar a mal estas coisas [como en el caso gallego], nem sempre se evitam certos dissabores"73.

En Gil Vicente, el "bobo" sí habla, como los "bobos" del teatro español posterior; sin embargo, sus discursos son inconexos, sin sentido, una burla de todo y de todos ${ }^{74}$. Son discursos que encierran, sin embargo, grandes verdades, que pueden ser dichas sin el menor pudor merced a la inocencia que caracteriza al loco vicentino. En ese sentido, el parvo es, como en el caso de las "máscaras" gallegas y transmontanas, irresponsable y, de igual modo que éstas no pueden ser culpadas por los daños físicos que causan a la gente, el parvo no puede ser culpado por el daño moral que sus juicios puedan causar a otros. Eso le permite el libre uso de la sinceridad (sinceritas) que, como acertadamente nota Cardoso Bernardes 75 , es uno de sus principales atributos, y es el que le permite la capacidad para emitir juicios sobre la moralidad de los demás. Sea como fuere, el loco vicentino comparte con las máscaras carnavalescas la incontinencia, así

\footnotetext{
72 Vicente Risco, “Etnografía...”, p. 623.

73 António Lourenço Fontes, op. cit., p. 112.

${ }^{74}$ Nos parecen, en este sentido, muy elucidativas las palabras de Cardoso Bernardes (Sátira e Lirismo..., cit., p. 242), al decir que el loco vicentino "transforma em cómico tudo o que é constritivo ou ameaçador". De este modo, según continúa señalando este investigador portugués, la sátira medieval se convierte en "uma via de exorcização do medo imposto pela Moral e, mais do que uma arma, é uma consagração da abertura do mundo a um processo de nivelamento, ainda que temporário".

${ }^{75}$ En Sátira e Lirismo..., cit., pp. 267-268. Sobre el papel moralizador, a la vez que cómico, del loco vicentino, ibidem, p. 271 y - en el caso particular del loco de la Barca do Inferno - p. 506.
} 
como el carácter primario, obsceno y casi animal de su lenguaje ${ }^{76}$. El loco vicentino sí habla, al contrario de las "máscaras" del Noroeste ibérico; frente a éstas, sin embargo, no agrede físicamente al público (o, por lo menos, no figura tal cosa en los textos), ahora bien... ¿no será el uso, descarado y directo, del "parvo" una especie de "agresión" más mordaz incluso que los golpes con bejigas y latiguillos de cuero? Luego habremos de volver sobre ello. En cualquier caso, la labor crítica es una actividad fundamental del bobo vicentino. Reocrdemos, a este respecto, que el bufón medieval (y, dentro de esta categoría, también el "parvo" vicentino) era, para Bajtín, el gran crítico de la sociedad medieval feudal 77 .

Por otro lado, esa facultad que permite al parvo decir libremente cuanto desee, e incluso burlarse de los personajes de la corte ante sus mismísimas narices, sin ser culpado por ello, es también una característica general del teatro vicentino, y no sólo del "parvo". Gil Vicente, como se comprueba en muchos de sus textos, tenía plena licencia y venia para increpar o corregir - en ocasiones socarronamente y a través del humor - los excesos cortesanos. Tal licencia ha podido dar pie a una insinuación de Laurence Keates, según la cual Gil Vicente podría ser una especie de "bobo de corte" o bufón, de modo que el parvo de la Barca do Inferno y de otros autos actuaría como portavoz de las ideas del dramaturgo, cual si fuese su alter ego ("he [G. Vicente] uses the parvo as an alter

\footnotetext{
${ }^{76}$ Véase, a este respecto, Stephen Reckert, Espírito e Letra..., cit., pp. 83-87, donde se analiza, justamente, el caso de la lengua del parvo de Inferno, cuya característica más subrayable es su obscenidad escatológica: "Joane é um caso de coprolália crónica", llega a aseverar (con total justicia) este estudioso (ibidem, p. 84). Joane es, en realidad, un ser apegado a la tierra, a la esfera de lo corporal, pero, por eso mismo, puede enjuiciar libremente a aquéllos que se sienten más "espirituales" o "sabios" (sin serlo). Sobre el apego de los parvos vicentinos a la ley del cuerpo y de la esfera terrenal, cfr. Teles, Cruz, Pinheiro, op. cit., pp. 85-92.

${ }_{77}$ Cfr. Bajtín, op. cit., pp. 87 y ss.
} 
ego" 78 , en palabras de Keates). Ésta sería también la razón que permite a nuestro autor proferir los disparates que se encuentran en el carnavalesco Sermão de Abrantes, del que más tarde hablaremos. La autorización de la que Gil Vicente disfrutaba, para poder hacer un uso de la palabra tan libre como el que se puede observar en dicho sermón se justificaba "obviously with reference to the liberty traditionally allowed to fools"79 (y máxime en Carnaval, añadamos).

No pensamos que Gil Vicente deba ser considerado un "bobo de corte" en el sentido más estricto del término (tampoco Keates llega, en su libro, a declararlo abiertamente), pero sí concordamos plenamente con el lusitanista británico en cuanto a sus apreciaciones relativas a las causas y manifestaciones de la espontaneidad del escritor portugués.

El ambiente de las celebraciones carnavalescas siempre ha estado muy relacionado con la locura. La locura, presente en el Carnaval pero, desde luego, no exclusiva de éste, es un tema predilecto del moralismo medieval y renacentista europeo. Esto nos invita, pues, a enlazar con el asunto de la locura, en cuanto éste se relaciona con el Carnaval.

Como todo el mundo sabe, las licencias permitidas en esta época del año llegan a menudo a provocar estados de demencia generalizada. Está claro que nadie ignora el frenesí que, cada año, se desata en Rio de Janeiro en la época de la que hablamos. En Verín o en Laza, las reglas normales de convivencia de subvierten también notablemente. En cierta ocasión, Leite de Vasconcelos ${ }^{80}$, refiriéndose al "entrudo" de Lisboa, denunciaba que era éste un "período según sus palabras - de loucura, de frenesi ou, antes, de estupidez", y que "era lícito proceder de todas as formas, exceptuando as normas da delicadeza e da

\footnotetext{
${ }^{78}$ Laurence Keates, The Court Theatre of Gil Vicente, Lisboa, Gráficas Telles da Silva, 1962, p. 29.

79 Ibidem.

80 Etnografia Portuguesa - VIII, cit., pp. 160 y ss.
} 
distinção, porque estava assegurado o exito dos actos brutais" ${ }^{\prime 2}$. En el antruejo lisboeta de 1922 - también según Leite de Vasconcelos - se eligió un "Rei da Folia"82, esto es, de la "parranda", pero también, en cierto modo (y etimológicamente), de la locura; este curioso "monarca" se subió al tren en Vila Franca de Xira y, llegado a la capital, descendió del convoy en la estación de Santa Apolónia y se paseó en procesión por las calles, precedido de un cortejo de alabarderos montados en burros ${ }^{83}$. Su propósito fundamental era, por supuesto, sumir la ciudad en un caos demencial, regido por la borrachera, el desenfado y la inconsciencia más absolutas. La misma inconsciencia con la que se desenvuelven los parvos vicentinos, auténticos "reis da folia", a su modo, y, en resumidas cuentas, hijos del Carnaval, como descencientes de los "sots" franceses medievales. Vasallos de la Locura, viven inmersos en el reino de ésta. No deja de ser interesante volver sobre un tema atrás esbozado: el hecho significativo de la violencia, verbal o física, infligida por las "máscaras" a los

\footnotetext{
${ }^{81}$ Leite de Vasconcelos, Op. cit., p. 160. Esas palabras son casi idénticas a estas otras (donde, sin embargo, desaparece la intención de censura moral de Leite de Vasconcelos), de Caro Baroja: "desde un punto de vista social, lo que imperaba [en Carnaval] era una violencia establecida, un desenfreno de hechos y palabras[...]; la inversión del orden normal de las cosas tenía un papel primordial en la fiesta", Caro Baroja, op. cit., p. 50.

${ }^{82}$ Las elecciones de un "Rey del Carnaval" (o de las famosas "Reinas del Carnaval") son antiquísimas; para Caro Baroja (op. cit., pp. 299-301) pueden proceder de las tradiciones relativas al rey que se elegía, en las Saturnalia romanas, para reinar por un día. Hay que recordar la tradición medieval (sobre todo en Navarra) del "Rey de la Faba" (ibidem, pp. 315320), que era coronado ... ¡el día de los Reyes Magos!. El trovador Alfonso Álvarez de Villasandino fue coronado Rey de la Faba, adquiriendo este título como una especie de "mote" en sus composiciones líricas, y sobre todo en las de otros poetas contemporáneos. Esa "faba" se relaciona, claro está, con el haba que, todavía hoy, suele esconderse en el roscón de reyes, y que concede buenos augurios (correspondientes a la "coronación" como Rey de la Faba) al afortunado comensal que da con ella en la consumición de ese pastel. Del Rex Saturnalium, en fin, descienden otros "monarcas" carnavalescos, como el "mazarrón" de Burgos y el "zancarrón" o "zangarrón" de Montamarta (prov. de Zamora), relacionados con el libertinaje carnavalesco y con la inocencia, y por tanto, con los Santos Inocentes y, por ende, también con el Poisson d'Avril francés.

${ }^{83}$ Ibidem, p. 147. Recuérdese el papel (casi mítico) del burro en las celebraciones carnavalescas (y para-carnavalescas) europeas medievales.
} 
viandantes durante las carnavaladas ${ }^{84}$. En el antruejo popular ibérico, no es raro que los transeúntes sean agredidos físicamente (aunque, por lo común, nunca llegan a sufrir, como es lógico, ningún tipo de lesión) por los enmascarados. Los parvos vicentinos eran mucho más sutiles. Fustigaban por medio de la palabra, particularidad esta que atañe a buena parte del conjunto de la obra vicentina, y no sólo a los autos en los que aparece el parvo. Ejemplo soberbio de esto son las famosas pulhas con las que el parvo es capaz de intimidar ni más ni menos que al mismísimo Diablo, en el Auto da Barca do Inferno. A éste, en efecto, le llama lindezas como las siguientes: "antrecosto de carrapato", "filho da grande aleyvosa", "neto de cagarrinhosa"85, "escomungado nas erguejas" 86, "perna de cigarra velha", "caganita de coelha"87, "pelourinho de Pampulha", etc..., aparte de declararle a la cara cosas como "tua molher he tinhosa/ \& ha de parir hum çapo", de decirle "burrella, cornudo sejas", o que su mujer "fogio/ pera a ylha da Madeyra" y otros insultos semejantes [1518: f. 3v.; 1562: f. 45v.]. Además, a partir de su aparición en escena, irá insultando también a buena parte de los distintos personajes que van acercándose a las barcas del Más Allá [1518 y 1562, passim]: al judío, por ejemplo, lo llama "guafanhoto d' Almeirim"88 [1518: f. 6v.]; al corregidor le dice "parecês me vós a my/ como cagado nebry/ mandado no Sardoall" [1518: f. 7v.], etcétera, etcétera... Hasta tal punto debieron dejar aplacado al pobre diablo vicentino estas pulhas, que el menino del siguiente auto

\footnotetext{
84 Violencia relacionada, para Caro Baroja, con ritos procedentes de las Lupercalia (op. cit., pp. 345-347). La tradición de fustigar con latiguillos o vejigas es muy común y la protagonizan máscaras de toda la geografía ibérica, desde las "botargas" de Guadalajara hasta los "choqueiros" y "cigarróns" de Galicia, pasando por las máscaras de Burgos, Aragón, etcétera, etcétera... (ibidem, pp. 357-367).

${ }^{85}$ Así en 1518; 1562: da cagarrinhosa.

86 "Erguejas": 1518 (arcaísmo, o popular); “ygrejas" (portugués culto, o más moderno): 1562.

${ }^{87}$ Así en 1518. Verso omitido en la versión de 1562.

88 Así en 1518; 1562: "carrapato d' Alcoutim".
} 
de las Barcas (la mal llamada Barca do Purgatório) todavía se acuerda de Joane, cuando el diablo lo intimida, llegando a apelar a la ayuda de aquél para acallar al Maligno, y llamándolo "nosso Joane": “Áquelle! S' eu chamar/ o nosso Joane!" [Cop., f. 54].

\section{[Gil Vicente y los sermones carnavalescos]}

La tradición de predicar sermones el Domingo de Carnaval (o, al decir portugués, el Domingo Gordo) es bien antigua. Evidentemente, el hecho de proferir una homilía casa muy bien con la fecha dominical en que comienzan las fiestas de antruejo. Lo que no es, desde luego, nada “canónico" es el tenor de las homilías carnavalescas, disparatadas y absurdas. Esta tradición del "sermón carnavalesco" se encuentra íntimamente ligada a otra, la de la elección, en fechas de Carnaval, de un Obispo cuyo cargo duraba lo que duraban las fechas de desenfreno y de mascaradas. La elección de estos obispos eran ya conocidas en la Edad Media, en que había la costumbre, en las ya citadas "fiestas de los locos", de nombrar a un Episcopus o Archiepiscopus Stultorum ${ }^{89}$. Estos episcopados farsescos se han mantenido, a nivel folklórico, en muchas partes de España, casi hasta nuestros días, aunque en muchos lugares, las "Fiestas del Obispillo" han ido retrocediendo. Antaño eran comunes los nombramientos de "Obispillos" el día de San Nicolás de Bari (6 de diciembre, fecha próxima a la de las Saturnalia romanas), cuyo obispado a veces se prolongaba hasta el Día de los Santos Inocentes (28 del mismo mes) ${ }^{90}$, es decir, uno de los días de los "locos"

\footnotetext{
${ }^{89}$ Caro Baroja, op. cit., pp. 311-314.

90 Caro Baroja, op. cit., p. 305-311.
} 
por excelencia, y en que más se muestra el carácter irresponsable, inocente del loco, y en que más se remarca el carácter salvífico de esa inocencia.

Los episcopi stultorum y los "obispillos", al igual que los obispos verídicos, tienen como un encargo especial el de sermonear a sus "fieles", es decir, a los "locos", o a los desenfrenados amigos de la parranda. Los Domingos de Carnaval, algún juerguista era también elegido como "obispo" o "predicador" para pronunciar un sermón carnavalesco. A uno de esos sermones, la Corte portuguesa invitó, cierta vez, a Gil Vicente, como vamos ahora mismo a ver.

Casi al principio del Sermão de Abrantes, pronunciado en esa ciudad ribatejana en el Domingo Gordo de 150691, Gil Vicente solicitaba de su público: “que me den licencia/ aquesta vez sola, ser loco por oy/ y toda su vida licencia les doy/ que puedan ser necios con reverencia"[Co., f. 251v.]. Esta declaración de intenciones, unida a la fecha en que tal sermón se pronunció, nos dejan clara evidencia del tipo de "homilía" ante la que nos encontramos. El público (suponemos que de manera jocosa) había mostrado sus "recelos" a que un laico predicase, como se señala en la presentación del sermón: “alguns foram em contrayro parecer que se nam preegasse sermão d' omem leygo" [f. 251]. Por ello, precisaba Gil Vicente explicar la "conveniencia" de su actuación, debiendo así pedir perdón a sus "detratores" [ibidem] y justificarse por ponerse como "perro en bragas d' acero" [ibidem].

\footnotetext{
${ }^{91}$ Debemos aquí recordar al tristemente desaparecido profesor M. Paul Teyssier, gran maestro de vicentistas, quien nos puso sobre aviso (en la lectura de nuestra tesis, cuyo tribunal presidió) respecto al carácter carnavalesco de este sermón. En efecto, el profesor Teyssier, aplicando el método del Calendario Perpetuo, había logrado descubrir que la "noyte do nacimento do Illustrissimo Iffante dom Luis", en que (según la Copilaçam, f. 513) se profirió el sermón, era la misma noche del Domingo Gordo.
} 
Tras haber dado licencia a sus juiciosos oyentes de ser toda su vida "necios con reverencia", les pide paciencia, puesto que su locura no va a pasar de una noche ("yo que lo sea [loco] esta noche, y no más", [ibidem]), permitiendo, sin embargo, a los que forman el auditorio, que sean locos donde y cuando quieran: "ayan paciencia/ que esta locura no passa de aqui/ y yo gela doy, que aqui y alli/lo sean por siempre, que es más preminencia" [ibidem]. Quiere decir que es consciente de que el carnaval no va a durar mucho más: no ha de pasar (por lo menos para él) de esa noche.

Desarrollará después una prédica llena de desatinos, que responde al tema non volo, volo et deficior, en que va a repasar todos los males de un personaje que se está muriendo, entendiéndolos como señales de su enfermedad... En ese "diagnóstico" se va pasando revista a todas esas señales de enfermedad, que en el principio de esta parte nos habían sido expuestas: "Nueve señales aveis de saber/ que tiene el enfermo que se quiere finar:/ lo primero es que pierde el gustar,/ y lo segundo el desconocer", etcétera [f. 252]. Pero, ¿qué enfermo agonizante es éste? Tradicionalmente, haciendo una lectura "seria" de este texto (que no tiene nada de serio) se ha querido identificar este enfermo, llamado por Gil Vicente "este mundo" [f. 252] con el Mundo, esto es, el Universo, el cual "se quiere finar" (quiere llegar a su fin, al Apocalipsis): sería, por tanto, una advertencia escatológica. Pero aquí vamos a hacer una lectura bien distinta.

Empieza nuestro autor diciendo lo que no quiere hacer en su discurso, y en toda su exposición nos va quedando claro que lo que no quiere es entrar en cuestiones de teología: si Dios es uno y trino [f. 251v.], en qué se ocupaba antes de crear el Mundo [f. 252], o qué fue antes, si el pecado o el infierno [iibidem], o (recojo el texto literal, que tiene enjundia) "si el fructo vedado/ si era mançana, 
o pera, o melón" [ibidem], y otros muchos absurdos semejantes, acabando por declarar que "concluyo el no quiero: que es/ mi voluntad naqueste sermón/ dexar los secretos d' especulación/ y dezir las cosas que tienen más pies" [ibidem, subrayado nuestro]. ¿Y qué cosas son éstas "que tienen más pies"? "Quiero deziros con grande querella [...]/ quiero deziros que moça y vieja/ y viejo, y moço, monja y frayle/todos andamos al son de su bayle,/vos y yo, y aquél, y aquélla" [ibidem, subr. nuestro]. Por eso son cosas con más pies: porque bailan. Vicente declara que nunca "huvo tanta fee/ con el Infierno como oy ha hi" [ibidem, subr. nuestro]. Este oy (=hoy) no es, como se ha querido entender, "nuestro tiempo": es el de día de hoy, es decir, el Carnaval. Acto seguido, dirá Gil Vicente que "este mundo no puede turar" y que este mismo mundo "se quiere finar", empezando así su diagnóstico sobre la agonía de "este mundo" [ibidem]. Hemos puesto intencionadamente "mundo" con inicial minúscula, porque no es el Mundo, sino el mundo del Carnaval o, mejor, el Tiempo de Carnaval, en que bailan mozos, viejos, niños y adultos.

Todo el largo parlamento en que Gil Vicente se refiere a los males de un mundo que agoniza, y que dentro de poco será preciso enterrar, se refiere en realidad a la agonía del Carnaval. Se trata de una festividad antigua, la del Entierro del Carnaval, en Porugal Enterro do Entrudo, con formas como el popularísimo "Entierro de la Sardina", en que un cortejo de enmascarados carnavaleros van cantando las loas del difunto, o avisando a las gentes de que Don Carnal "se nos muere", o que "le queda poco tiempo de vida", haciendo llantos fingidos, etcétera... El propio Gil Vicente declara que el tiempo que se está acabando es el Veneris Seculum [f. 253v.], y acaba diciendo que "es por demás aqueste sermón", pidiendo perdón a Dios (suponemos que por sus “desmanes") y pidiendo a la Virgen y a Cristo "que nos dee muerte con nuestra 
vitoria" [ibidem]. En algunos versos finales se dice que "es por demás predicar verdad", "clamar por virtud", "traeros salud", "reprender maldad", "loar la bondad", "quebrar la cabeça", y, en fin, todo eso y mucho más "es por demás, ¡que tanto se os daa!” [f. 253v.]. El que se muere es el Carnaval. El Sermão de Abrantes debe ser considerado como eso, como una impenitente burla, un típico sermón de "Entierro de la Sardina". Todas las interpretaciones "serias" de esta peculiar "homilía", a nuestro entender, y usando las mismas palabras de Gil Vicente, son "por demás".

Gil Vicente, lo "inferior" y lo inconsciente

Para Bajtín92, los desmanes carnavalescos cumplían un cometido fundamental, el de facilitar un canal de expresión a lo ridículo, a las necesidades reprimidas de lo carnal, de lo instintivo, de lo "bajo" y grotesco, usando la transgresión, "sacando afuera" lo que estaba siempre oculto, reprimido; esta represión se refiere tanto al sentido moral como al fisiológico, abarcando, pues, una inevitable atención a todo aquello que se "retiene" por la fisiología, pero debe "salir" por alguna parte: la orina, las heces, mucosidades, esperma, flujo vaginal... Un ejemplo cumplido de esta "incontinencia" carnavalesca es, desde luego, una vez más, el "parvo" de la Barca do Inferno, Joane, felicísimo hallazgo de la imaginación cómica vicentina. De sí mismo llega a decir, este personaje, cuando el diablo le pregunta que de qué murió, que lo hizo "de caganeyra", y cuando el demonio, pasmado, pregunta "de que?", Joane declara “de caga merdeira", injuriándolo después de este modo: "maa ravugem que te dê!" [1518, f. 3v.; 1562: f. 45v.]; al mismo lo llama "neto de cagarrinhosa", "caganita 
de coelha", etc..., como hemos visto anteriormente; del judío dice que "elle mijou nos finados/ n' eergueja de Sam Giaão"93 [1518, f. 6v.; 1562: 47v.], etcétera...

Este primado de lo "bajo", de lo inferior en el terreno fisiológico, pero también en lo moral y psicológico (piénsese en la locura) conlleva una catábasis, un descenso a lo inferior por excelencia: el infierno; también se relaciona con la muerte, que significa la degradación total del individuo, por lo menos en su materialidad, en su fisiología ${ }^{94}$. Curiosamente, tal apreciación no parece tener cabida en relación con el "parvo" de Inferno: éste, a pesar de su ridiculez, de sus obscenidades, pertenece al "número de los justos", merced a una particularidad de excepcional importancia: su simpleza, es decir, su inocencia libre de culpa ${ }^{95}$. Inocencia que le merece la salvación. Así, el Ángel le dice: “Tu passarás se quiseres,/ porque em todos teus fazeres/ per malicia nom erraste./ Tua simpreza $t^{\prime}$ abaste/ para gozar dos prazeres [celestiales]" [1518: ff. 3v./ 4; 1562: f. $45 \mathrm{v}$.$] .$

Y, después de todo, hay que tener en cuenta que la catábasis no es sólo un descenso al infierno,en el sentido de condena, sino también un descenso al interior de uno mismo, a lo más recóndito y profundo del ser humano. En este sentido, es especialmente significativo el derrotero esencial de la Comedia dantesca: no se puede llegar al cielo sin sumergirse en el Averno hasta sus mayores profundidades.

\footnotetext{
93 Así en 1518; 1562: "e s' elle mijou nos finados/ no adro de Sam Gião".

94 Cfr. Bajtín, op. cit., pp. 332-393.

95 En este sentido, también debe ser relativizada la identificación, casi absoluta, establecida por Bajtín entre el "loco" o "bufón" y el Diablo, identificación que tiene su expresión máxima en los celebérrimos disfraces de diablos corrientes en todo carnaval que se precie: cfr. Bajtín, op.cit., pp. 237-240.
} 
Pero vamos ahora a analizar otra potencialidad de la relación con lo "bajo", con las profundidades de uno mismo. Nos referimos a la idea de servidumbre de la conciencia en relación con lo subconsciente. Un tema que ha sido magistralmente tratado por Gil Vicente. El loco, el "parvo", es, desde luego, el símbolo más apropiado para significar la psique oscura, primaria, que subyace a toda inteligencia humana. El subconsciente, según Freud, o inconsciente, según Jung ${ }^{96}$, es más fuerte que la voluntad, la limita, la constriñe, la obliga a prestarle servicios, la atormenta con exigencias y la condena a servidumbre.

En un auto de Gil Vicente, la Floresta de Enganos, se nos presenta, nada más comenzar, a un filósofo con un parvo atado a un pie [cop., f. 114, en didascalia: "entra logo o Philosofo com o parvo atado ao pee"]. El sabio declara haber dado consejos a los "muy antigos Romanos" [f. 114], logrando que a pesar de su tiranía inicial, aceptasen los "consejos muy sanos" [ibidem] del filósofo vicentino. Pero como "la reprehensión/ a todos es enojosa", el pobre sabio cayó "en grande passión" y acabó por ser encerrado "en prisión,/ en carcel muy tenebrosa" [ibidem]. Esta "cárcel tenebrosa" es una magnífica representación de las tinieblas de lo inconsciente. Pero, por si fuera poco castigo, "ataron ansi comigo/ este bovo que aqui veis" [ibidem]. El sabio deberá traerlo y llevarlo siempre, para ir a comer y a dormir, y a donde sea, no pudiendo acabar su condena hasta la hora de la muerte [ibidem]. A lo largo de los primeros versos de la Floresta de Enganos [ff. 114, r. y v.], veremos cómo el filósofo intentará desarrollar un discurso coherente, mientras que el bobo que lo acompaña lo interrumpirá constantemente, para decir sandeces, o para revelar

\footnotetext{
96 Es innecesario dar nombres de obras, ya que la noción de "subconsciente" en la obra de Freud, y de "inconsciente", en la de Jung, se encuentran diseminadas por todo el conjunto de las vastísimas obras de ambos escritores.
} 
deseos ocultos de su "dueño": su inclinación hacia "las mochachas que aqui están", por ejemplo, o si son mejores para comer "las grajas o los milanos"... [114v.]. El parvo sólo quiere dormir "quatro o cinco meses", e invita al sabio a dormir con él: "hechaos vós/ y dormiremos a la una" [ibidem].

Este parvo es el loco que todos llevamos dentro, el otro lado de nuestra psique, que nos hace comportarnos de un modo irracional en ocasiones. Sobre todo en el Carnaval, en la fiesta de los Locos por antonomasia, de la cual procede el arquetipo del parvo vicentino. Podemos decir que Gil Vicente, en su Floresta de Enganos, anticipó en muchos siglos algo que no se ha conocido con exactitud hasta los descubrimientos de Freud, pero que siempre se ha intuido: el lado oscuro de la psique humana. 